Running head: META-ANALYSIS ON IDENTIFICATION AND COLLECTIVE ACTION 1

Social Identification and Collective Action Participation in the Internet Age: A Meta-Analysis

\author{
Serap Akfirat ${ }^{1}$, Mete Sefa Uysal ${ }^{1}$, Fatih Bayrak ${ }^{2}$, Tolga Ergiyen ${ }^{3}$, Emir Üzümçeker ${ }^{1}$, Taylan \\ Yurtbakan $^{1}, \&$ Özlem Serap Özkan ${ }^{1}$ \\ ${ }^{1}$ Dokuz Eylul University, Department of Psychology \\ ${ }^{2}$ Baskent University, Department of Psychology \\ ${ }^{3}$ Izmir University of Economics, Department of Psychology
}

Author Note

Correspondence concerning this article should be addressed to Serap Akfirat, Department of Psychology, Dokuz Eylül University, Izmir, Turkey. E-mail:

serap.akfirat@deu.edu.tr

We dedicated this study to George Floyd and the Black Lives Matter movement.

All data and materials are accessible at

https://osf.io/tf5zp/?view_only=e3c13743d63a4d5b889d369b3d5dc0dc 


\begin{abstract}
Since the digitally-mediated large-scale protests took place all over the world, the role of social identities in collective actions has become the focus of academic attention. Some scholars claim that interpersonal or individual reasons have become more important than collective identifications in predicting participation to digitally-mediated collective actions. To answer the question that whether social identification has lost its centrality in collective actions in the Internet age, we conducted a meta-analysis of 40 studies $(N=16,933)$ which examined digitally-mediated collective actions between 2011 and 2020 across the world. We studied the relationship between social identification and collective action, and the possible moderator effects of group type to be identified (emergent group/pre-existing group), participation type (behavior/intention), and WEIRDness of the sample. The analyses showed a moderate to strong relationship between social identification and collective action participation, while group type was found the only significant moderator. Accordingly, the relationship between collective action participation and identification with emergent groups was much stronger compared to the relationship between identification with pre-existing groups. We discussed the theoretical implications of the results that highlight the basic dynamics of collective actions.
\end{abstract}

Keywords: social identification, collective action, connective action, social media, digital platforms 


\section{Social Identification and Collective Action Participation in the Internet Age: A Meta-}

\section{Analysis}

The role of digital technologies in collective actions has been drawing attention from a wide range of disciplines such as sociology, political science, communication, and psychology (e.g., Carlisle \& Patton, 2013; Castells, 2015; Harlow \& Guo, 2014; Postmes, Spears, \& Lea, 2002; Smith, McGarty, \& Thomas, 2018). Especially with the occurrence of the digitally-mediated large-scale protests across the world (e.g., Arab Spring in Tunisia and Egypt, Occupy Movements in the US, Gezi Park Protests in Turkey, and Yellow Vest in France), studies on the relationship between digital communication and collective action have increased.

Some scholars suggested that collective actions have been changed since organizing social movements have become easier, faster, and cheaper in the Internet age than in the previous times (e.g., Bennett, Breunig, \& Givens, 2008; Garrett, 2006). Accordingly, collective actions organized through social media or other digital platforms are qualitatively different from the traditional ones, because their logic is different and they have become individualized. Therefore, collective actions in the Internet age do not work based on shared social identities, they do not need organizing institutions or leaders any longer (Bennett et al., 2008; Bennett \& Segerberg, 2012; Earl \& Kimport, 2011). On the other hand, scholars mostly from the social identity approach view collective actions as the phenomena that share the basic social psychological process whereby such factors as social identity, collective efficacy, and perceived injustices interplay (e.g., Postmes et al., 2002; Smith, Gavin, \& Sharp, 2015; Stott et al., 2018; Thomas, McGarty, Lala, Stuart, Hall, \& Goddard, 2015), whether or not organized through social media. Collective action requires the social categorization process and there should be an "us" and the "them" (Drury \& Reicher, 1999; Vestergren, Drury, \& 
Chiriac, 2018). Thus, social identification is considered as lying at the heart of all kinds of collective actions.

In the current study, we provide the results of a meta-analysis on the relationship between social identification and participation to the collective actions between 2011 and 2020, in the Internet age. We aim to contribute to the debate of whether collective actions in the Internet age differ qualitatively from the conventional ones. We focus on clarifying the role of social identification in participation to digitally mediated collective actions. We also examined the possible moderator effects of group type (emergent group/pre-existing group), participation type (behavior/intention), and WEIRDness of sample (western, educated, industrialized, rich, and democratic) on the relationship between social identification and collective action participation.

\section{Social psychological accounts of collective action}

Collective action is defined as the joint conduct of group members who aimed to improve the position of their own group or to reach a common group goal (Wright, Taylor, \& Moghaddam, 1990). The well-known approaches of collective action are based on the findings that social identification is either the strongest predictor of collective action participation or play an essential role in mobilization and participation (e.g., Drury \& Reicher, 2009; Jost et al., 2012; Klandermans, 1997; Priante, Ehrenhard, van den Broek, \& Need, 2018; Stürmer \& Simon, 2004; van Zomeren, Postmes, \& Spears, 2008). For instance, The Elaborated Social Identity Model of Crowd Behavior (ESIM; Drury \& Reicher, 1999, 2000; Reicher, 1996) posits that collective actions are fundamentally group phenomenon and characteristically intergroup encounters because only shared self-categorization provides definitions of appropriate and possible conduct, and in turn, enable people to act collectively.

Studies also showed that to act collectively a) group members should develop a shared understanding on their group is illegitimately or unfairly oppressed, disadvantaged, or 
deprived (Ellemers, 1993; Mummendey, Kessler, Klink, \& Mielke, 1999; Tajfel \& Turner, 1986; van Zomeren et al., 2008) which give rise group-based anger, moral outrage, or resentment (Thomas, McGarty, \& Mavor, 2009; van Zomeren, Spears, Fischer, \& Leach, 2004), b) they should perceive that they can do something as a group to change the situation, usually conceptualized as collective efficacy (Thomas, Mavor, \& McGarty, 2012; van Zomeren, 2013). Developing such a common understanding on these two factors that make collective actions possible would be the result of the interaction between intergroup context (e.g., unfair treatment of outgroup) and intragroup processes (e.g., consensualization process) (Drury \& Reicher, 2000; Haslam, Turner, Oakes, McGarty, \& Reynolds, 1998; Reicher, Haslam, \& Hopkins, 2005; Vestergren et al., 2018). Therefore, collective actions are characteristically group-level phenomena that encompass both intra- and intergroup processes (Drury \& Reicher, 2000; Reicher, 2001; Stott \& Reicher, 1998).

Furthermore, research reveals that the most influential individuals that shape common understandings are the most prototypical group members or group representatives (Hogg \& van Knippenberg, 2003; Platow \& van Knippenberg, 2001; Turner \& Haslam, 2001), which indicates that the shared understandings on the intergroup context (e.g., "we are illegitimately treated") and intragroup factors (e.g., "we should do something") might be reached through a leadership process. In the collective actions previous to the widespread use of digital technologies, this leading charge was usually, but not necessarily, on to the shoulders of the leaders of formal organizations such as political parties or labor unions (Klandermans, 1984, 1997). In other words, in the process of collective mobilization, the role of framing or shaping the understandings of ingroup members was played by the conventional organizations and their leaders (Bimber, Flanagin, \& Stohl, 2005).

\section{Connective action as the new form of collective action}


Digital technologies, as a new tool of communication, organization, and mobilization have transformed collective actions (Bennett \& Segerberg, 2012; Postmes et al., 2002; Thomas et al., 2015). Some scholars proposed that collective actions have undergone a qualitative transformation especially due to the widespread use of digital technologies (e.g., social media) that allow for user-generated content, and make possible for individuals to comment, share, and circulate the contents (e.g., Bennett et al., 2008; Leong, Pan, Bahri, \& Fauzi, 2019; Vaast, Safadi, Lapointe, \& Negoita, 2017). Accordingly, digital technologies have a huge impact on collective actions via making mass communication possible and the basic characteristic of collective actions, being a group-level phenomenon, has transformed into a new form (Bennett \& Segerberg, 2012). This new form, connective action, has a distinct logic because it operates at interpersonal or even at an individual level rather than working based on shared social identities (Bennett et al., 2008; Bennett \& Segerberg, 2012; Earl \& Kimport, 2011).

Bennett and colleagues (2008) asserted that compared to conventional social movements, connective action is far more personalized, and its underlying psychological mechanism does not require the symbolic construction of a united $u s$. The connective action participants do not need to develop common understandings or to have a shared ideological frame to make connections (Bennett \& Segerberg, 2012). These digital connections are made based on interpersonal relations such as friendship or family. Each participator in digitallymediated collective actions has its own reasons or concerns for attending, simply because each has a unique combination of individual goals, motives, and interpersonal style. Bennett and Segerberg (2012) claimed that these individualized orientations result in engagement with politics as an expression of personal hopes, lifestyles, and grievances. Individuals reinterpret grievances and re-create their personal meanings in their social media networks. In line with the conceptualization of digitally-mediated collective actions as a personalized mode of 
actions, Bennett, Segerberg, and Walker (2014) suggested that social media serve as stitching mechanisms that connect different networks into the coherent organization in the absence of recognized leaders, common goals, or conventional organization.

In a study on Umbrella Movement, the Hong Kong democracy protests, Lee, Chen, and Chan (2017) stated that people engaged in both the collective action of public space occupation and a diverse range of personalized or small-group based actions (e.g., public art creation, attending "civic seminars", and participating in frontline actions such as setting up road blockades). Nekmat, Gower, Zhou, and Metzger (2015) also showed that receiving messages from personal networks (e.g., friends) are stronger predictors of willingness to participate in collective activities on social media than receiving messages from impersonal ones (e.g., organizational sources). Bennett and colleagues (2014) admit the findings of research on the Arab Spring (e.g., Tufekci, 2013) and Umbrella movements (e.g., Tang \& Lee, 2013) as evidence for their arguments. Accordingly, these findings indicate that individuals participated in collective actions through social media, because social media had given people the opportunity to directly connect with political actors or opinion leaders or "networked microcelebrities". Anduiza, Cristancho, and Sabucedo (2014) also showed that the main mobilization channels were personal contacts and online social networks rather than the members of formal organizations or broadcast media in the 15-M movements in Spain. Therefore, they concluded that the 15-M movement significantly differed from the traditional collective actions in terms of the characteristics of staging organizations (recently created, without formal membership and scarce resources).

To summarize, the logic of connective action differs significantly from the logic of traditional collective action which requires shared understandings and common group goals. Now, digitally-mediated collective action operates at the interpersonal level rather than grouplevel. The individual participators mostly have their unique combination of individual motives 
for participation. Following the logic of connective actions, one can infer that the relationship between social identification and collective action participation has weakened in the Internet age; and social identification might even have lost its predictive power of collective action participation, especially if those actions are mediated by digital platforms.

\section{The current study}

In the present study, we addressed the role of social identification in collective action participation in the Internet age. We conducted a meta-analysis of the recent studies between 2011 and 2020 which examined digitally-mediated collective actions (e.g., Arab Spring, Occupy Wall Street, Hong Kong, Yellow Vest, and Gezi Park protests). In the previous studies, group identification appeared as the strongest predictor of collective actions (for a meta-analytic review see van Zomeren et al., 2008), including those which were organized through digital platforms (for a systematic review see Priante et al., 2018). If the assumption that social identification has lost its crucial role in collective action is valid, we should expect that social identification would have a small effect size in predicting participation in collective actions organized through digital technologies (e.g., Facebook and Twitter).

While group identification was found as the strongest antecedent of collective actions in previous studies (Priante et al., 2018; van Zomeren et al., 2008), the increased use of digital platforms that gave rise questioning the mechanisms of collective actions led to a need for the current study. Besides, studies on this topic are diverse with contributions from multiple disciplines that use various theoretical and methodological approaches. Such heterogeneity requires to be addressed by a meta-analytic study which enables us to determine a) the degree of variability of the effects of different studies and b) if there would be considerable variations, how much of these variations could be credited to which factors, i.e. moderators (see Cooper, Hedges, \& Valentine, 2009). Therefore, we also aimed to test the effects of possible moderators: group type, participation type, and WEIRDness of the sample. 
Group type. The concept of social identification and the modes of identity are central to the discussions on the similarities and the differences between conventional ways of participating in collective actions and mobilization through digital tools (Alberici \& Milesi, 2016, 2018; Chan, 2014, 2016). It has been suggested for a long time that the different modes of social identities might affect participation in collective action (Kelly \& Brienlinger, 1995; Klein, Spears, \& Reicher, 2007; Simon \& Klandermans, 2001; Stürmer \& Simon, 2004). Van Zomeren and colleagues (2008) showed that identification with politicized identity such as action groups had a stronger effect size than identification with the pre-existing groups $(r=$ .43 vs. $r=.34)$. In addition, there are also a number of studies showing identification with emergent groups are strong predictor of participation to digitally mediated collective action (e.g., Chayinska, Minescu, \& McGarty, 2019; Odağ, Uluğ, \& Solak, 2016; Smith et al., 2015). It seems important to take the aforementioned findings of van Zomeren and colleagues (2008) one step further, and to examine whether identification with an emergent group (e.g., protestor groups, opinion-based groups) better predicts participation to collective action comparing to the identification with pre-existing social groups (e.g., nations, religious groups, ideological groups, etc.). Based on previous findings, we expect that identification with emergent groups would have a higher effect size in predicting collective action participation comparing to the identification with pre-existing groups.

Participation type. While some of the collective action studies measured actual participation behavior (e.g., Chan, Catteneo, Mak, \& Lin, 2017; Thomas et al., 2015), the others just focused on the intention of participation (e.g., Alberici \& Milesi, 2013; Morgan \& Chan, 2016). The theory of planned behavior (Ajzen, 1985) asserts that intention is a robust predictor of human behavior, which has been evidenced by numerous studies regarding a wide range of conducts including collective action (Kelly \& Brienlinger, 1995; Park \& Yang, 2012). Despite some findings support the notion that intentions and behaviors are closely 
linked, the results of a meta-analysis (Webb \& Sheeran, 2006) showed that a large change in intention resulted in a small change in actual behavior. Likewise, another meta-analysis by Rhodes and Dickau (2012) demonstrated that changes in intention did not result in a significant change in behavior. Therefore, we thought that the strength of the relationship between social identification and collective action might vary depending on participation type (i.e., behavior or intention).

WEIRDness. The vast majority of research in psychology has been carried out with WEIRD (western, educated, industrialized, rich, and democratic) samples (Henrich, Heine, \& Norenzayan, 2010a). In these studies, it is assumed that human populations have a very small variation and these samples represent the universe (Henrich, Heine \& Norenzayan, 2010b). However, the WEIRD samples represent only a small part of the real world (Arnett, 2016), and findings on topics such as self-concepts (e.g., Morling \& Lamoreaux, 2008), reasoning styles (e.g., Norenzayan, Smith, Kim, \& Nisbett, 2007; Uskul, Kitayama, \& Nisbett, 2008), categorization (e.g., Atran et al., 2001; Waxman \& Medin, 2007), cooperation, and fairness (e.g., Henrich et al., 2005; 2006) might not be valid in different macro-contexts (Henrich et al., 2010b). Collective actions have a substantial variety that they occurred in different contexts in many different regions and cultures of the world (see van Zomeren et al., 2008). Whereas numerous studies focused on the relationship between social identification and collective action in underrepresented and non-WEIRD societies, to the knowledge of authors there is no study that examines whether the macro-context in which the collective actions take place moderates this relationship. In this vein, we argue that the WEIRDness of samples should be taken into account to better understand the relationship between social identification and collective action.

To summarize, in the present meta-analysis, we aimed to examine the relationship between social identification and collective action participation in the Internet age. Given the 
fact that the studies included in the meta-analysis are broad and diverse in terms of context, methodology, and sample, we also expect a considerable amount of heterogeneity. Therefore, we also attempt to specify how much of the assumed heterogeneity could be attributed to the group type, participation type, and WEIRDness of the sample.

\section{Method}

\section{Inclusion Criteria and Literature Search}

To choose the studies that should be included in the meta-analysis, we used the three following criteria. Our first criterion was that the studies should have included the measures of both social identification and participation in collective action variables. Secondly, to make sure the collective action examined in the study was digitally mediated, we chose the studies (1) that were on the large scale collective actions which are known to be overwhelmingly mobilized through digital platforms (e.g., Occupy Movements, Gezi Park Protests, Arab Spring, and Yellow Vest) or (2) that the authors stated the examined collective action was digitally mediated. Thirdly, we included the studies that contain Pearson's $r$ as an indicator of the relationship between social identification and collective action participation. When studies did not provide the correlations upon which analyses were based (i.e. because they only reported standardized or unstandardized coefficients), we contacted the author(s) and asked them to provide the necessary statistics. ${ }^{1}$

For the relevant studies, we performed a comprehensive search in the database Web of Science (WoS). In this search, we used the related search terms and their variations in the title, abstracts, and keywords of the articles ${ }^{2}$. We reached 1894 articles as a result of the WoS search. Then we refined the results by limiting the web of science categories. Because a huge range of categories are presented by the database from engineering to medicine, we made sure that only the directly relevant categories were included in our search such as communication,

\footnotetext{
${ }^{1}$ We contacted the authors of 18 studies in which Pearson's $r$ was not reported. The six of them responded to us providing the necessary statistics (a response rate of 33\%).

${ }^{2}$ The list all search terms can be seen at the project page on OSF.
} 
political science, political psychology, social psychology, and so on in this phase. After limiting the categories, we got 758 articles, and read the abstract of each. We removed 603 articles based on abstract reading and reached 155 relevant articles as a result. Then, we examined the full texts and decided to include 22 papers which met our including criteria. After that, we searched the reference lists of these 22 papers and found 8 more relevant papers. We also made a call for unpublished or nearly published studies via social media and mail groups, and the authors sent 3 unpublished papers to us. ${ }^{3}$ Finally, we included 40 studies with different samples published in 33 papers between 2011 and 2020. The whole research plan and inclusion criteria are presented in the diagram (see Figure 1). All data are accessible at https://osf.io/tf5zp/?view_only=e3c13743d63a4d5b889d369b3d5dc0dc

Insert Figure 1 about here

\section{Data Coding}

The relevant data from each study were extracted and coded the sample sizes and effect sizes by each author. The discrepancies between the authors were checked and resolved through consensus. Basic sample descriptors included sample size $(N)$, mean age, the standard deviation of age, percentage male/female in the sample, and country of the sample (see Table $1)$.

Insert Table 1 about here

\footnotetext{
${ }^{3}$ The call for unpublished data can be seen at the project page on OSF.
} 
Then, 3 pairs of authors coded each of the moderator variables (group type, participation type, and WEIRDness) independently. That is, each moderator variable was coded by 2 different coders. We calculated Cohen's (1960) kappa to measure the level of inter-rater agreement for each moderator. Firstly, the two authors coded the group type of each study (i.e. whether the social group was an emergent group specific to the action or preexisting groups such as gender, race, or political party). The Cohen's $k$ for group type was .88, which also indicates a high percentage of agreement between coders. Secondly, the other two authors coded participation type (i.e. whether people participated in a real collective action or reported their intention to participate) for each study. The Cohen's $k$ for participation type was .89 , which suggests a high inter-rater agreement. Thirdly, the other two authors coded the WEIRDness of the sample for each study (see Table 2), which resulted in a complete agreement. ${ }^{4}$ Where disagreements regarding the moderators were there, all of the authors re-checked the studies individually, and consensus was reached through discussion.

Insert Table 2 about here

\section{Analysis}

We conducted all of the analyses with Jamovi software (version 1.1.9, 2020) using the MAJOR package (version 1.0.2). We transformed correlation coefficients into Fisher Z correlation coefficients for analysis and back-transformed for results. This transformation allowed us to consider the sample size. We interpreted results by Cohen's (1992) guidelines which pointed small $(r=.10)$, medium $(r=.30)$ and large $(r=.50)$ effects. In accordance with the wide range of sample populations, we used the random-effects model which assumes that effects sizes can vary across studies. We analyzed effect sizes obtained through the reported

\footnotetext{
${ }^{4}$ We used the same WEIRDness categories as in Many Labs 2 (Klein et al., 2018) except for Singapore. We included Singapore into WEIRD category.
} 
correlation coefficients between social identification and collective action participation. For studies that reported multiple correlations, for example between two subscales of social identity and collective action participation, we took the average of all relevant correlations (Cooper et al., 2009). ${ }^{5}$

\section{Results}

\section{Descriptive Characteristics}

Across the 40 studies, the total number of participants was 16.933 , of which $58.78 \%$ were female. The mean age of the participants was $30.56(S D=8.81)$ years.

\section{Overall Effect Size}

We included the 33 studies (with 40 different samples) in the current meta-analysis. The average correlation between social identification and participation to collective action is $r_{z}=.45(95 \% \mathrm{CI}[.381, .522], Z=12.6, p<.001$, see Figure 2$)$. Results revealed that there is a moderate to strong (Cohen, 1992) positive relationship between social identification and participation in collective action. That is, higher identification is associated with frequent participation in collective action. A Cochrac's Q test was conducted to examine heterogeneity. Results indicated that there is significant heterogeneity across studies $(Q(39)=$ 852.70, $p<.001$, see Figure 2 and Figure 3). Besides, according to Higgins and Thompson (2002), $I^{2}$ is a useful and strong indicator of heterogeneity. In the present study, results $\left(I^{2}=\right.$ $95.16 \%$ ) indicate that the substantial variance depends on the variability in true effects size rather than depending on sampling error. Therefore, it can be concluded that there are some potential moderators to explain the amount of heterogeneity.

Insert Figure 2 about here

\footnotetext{
${ }^{5}$ In Thomas et al., (2015) both real participation in collective action and intention were measured by the same scale. Since the items assessing the real behaviors seem to be more concrete evidence, we considered the scale as a measure for real participation rather than a measure for intention.
} 


\section{Assessing Publication Bias}

We announced to retrieve as many unpublished studies as possible. However, there is a limited amount of unpublished study $(n=3)$ included in the meta-analysis. First, according to visual inspection, there is an asymmetric distribution which is an indicator of no publication bias (see Figure 3). Moreover, Egger's test provides substantial evidence. Funnel plot asymmetry was not significant for the association between social identification and participation to collective action $(z=.91, p=.364)$. Lastly, we also checked Orwin's (1983) Fail-Safe $N$ (40) suggesting that there would be more than 40 studies for reaching a slight effect size. Therefore, regarding evidence, we concluded that there is no sign of publication bias.

Insert Figure 3 about here

\section{Moderation Analysis}

The results indicating heterogeneity suggested that there are substantial moderators. Therefore, we conducted a subgroup analysis for the potential three moderators (group type, participation type, and WEIRDness). Results showed that the group type (emergent group or pre-existing group) significantly moderates the relationship between social identification and participation to collective action, indicating that the relationship was stronger for emergent group identification $\left(r_{z}=.52,95 \%\right.$ CI $\left.[.436, .600]\right)$ than pre-existing group identification $\left(r_{z}=\right.$ $.34,95 \%$ CI $[.228, .450])$. All other moderators were not significant ( $p s>.05)$. The results were presented in Table 3.

Insert Table 3 about here 


\section{Discussion}

In the present study, we aimed to examine the relationship between social identification and collective action participation through a meta-analysis, and thus, to contribute to the literature regarding the debate on the underlying mechanisms of collective actions in the Internet age (i.e., whether collective actions still do work on the basis of shared social identities). The results showed that there was a moderate to a strong relationship between social identification and participation in the digitally-mediated collective actions. In addition, we examined the role of some potential moderators (i.e. group types to be identified, participation type in collective action, and WEIRDness of the sample). The relationship between collective action participation and identification with emergent groups was found stronger compared to the relationship between collective action participation and identification with pre-existing social groups, while none of the other moderators had a significant effect. These results highlighted the importance of the two points regarding the research question of whether underlying social-psychological mechanisms of collective actions in the Internet age are the same as those previously.

First, the current meta-analysis indicated that the studies provide empirical support for collective action, not for the connective action which is basically proposed as a substitute for collective action in the Internet age. The concept of connective action was suggested as a new form of collective action that does not work based on shared social identities (Bennett et al., 2008; Earl \& Kimport, 2011). Rather, this new form of action has been considered as relying on (inter)personal digital connections, which make the process of collective action individualized. If people have participated in digitally-mediated collective actions based overwhelmingly on their individual or interpersonal connections or motivations, results would have shown a weak relationship between social identification and participation. In contrast, our results revealed that social identification is the strong predictor of collective action 
participation even in the Internet age. In other words, consistent with the social identity perspective, collective actions, including those that are organized through social media, seem to share the basic social psychological dynamics (e.g., Postmes et al., 2002; Stott et al., 2018; Thomas et al., 2015). This result is also consistent with the previous studies that found social identification was the strongest predictor of collective action participation (e.g., Jost et al., 2012; Klandermans, 1997; Stürmer \& Simon, 2004; van Zomeren et al., 2008; for a systematic review see Priante et al., 2018).

Second, we also found that the relationship between collective action participation and identification with emergent groups were stronger than identification with pre-existing groups. This finding implicates that social identification process of collective action might have transformed to some extent in the Internet age. The nature and formation of social identities in the Internet age have been discussed by the researchers from social identity tradition since the collective actions started to be organized through digital platforms. For example, Postmes and Brunsting (2002) argued that digital platforms endorse the promotion of social identity and the formation of new ingroups by influencing the ability to express behavior and the formation of new social identities by reducing the accountability of users. There are also more recent models drawing attention to the changing nature of social identity in digitally-mediated collective actions such as The Social Identity Model of Collective Action (SIMCA; van Zomeren et al., 2008), The Encapsulated Model of Social Identity in Collective Action (EMSICA; Thomas et al., 2009, 2012), and The Identity-Norm Nexus Formation Model (INN; Smith et al., 2015). McGarty, Thomas, Lala, Smith, and Bliuc (2014) proposed that social movements in the Internet age have involved a process by which people previously share similar ideas come to see themselves as a coherent social group or form opinion-based groups throughout communication on digital platforms, as the intergroup context demands (see also Bliuc, McGarty, Reynolds, \& Muntele, 2007; McGarty, Bliuc, 
Thomas, \& Bongiorno, 2009). Thomas and colleagues (2015) asserted that social media helps the formation of a contextually meaningful social identity and that social identification may emerge from the appraisal of injustice and group efficacy beliefs. Similarly, according to the INN model, social movements are not defined by pre-existing groups, ideologies, or identities in the Internet age anymore. Rather, they are driven by the participants' shared aspiration for social change which provides the basis for forming the new ingroup and developing a social identity. Despite some differences, the common point of the recent models is that all suggest digitally-mediated collective actions mostly rely on the emergent identities which are typically specific to the action context (e.g., protestor identity).

Considering the finding that collective action participation correlated strongly with emergent identities than with pre-existing group identification, which is also in line with the assumptions of the recent models mentioned above, digital communication appears to help formation of new ingroups, and to facilitate identification with newly formed context-specific protestor groups. Although it might be plausible concluding that forming new groups and identifying with emergent groups become more essential than identifying with pre-existing groups regarding large scale collective actions organized through digital platforms, one must be cautious when reaching such an inference. Given the fact that the studies in the current meta-analysis were conducted either during the collective actions or just a short while later, it is also possible that people have participated in the collective actions simply because their formal organizations or ideological groups might have demanded it. But afterward, the same people would have started to identify with the emergent group stronger than their identifications with the pre-existing group. This might have been because of the transformative effect of experiencing the collective action itself that the self-categorizations of crowd members might change as a function of their interactions with the out-group during the action, and a social identity that doesn't exist previously may develop as a function of 
intergroup dynamics (Drury \& Reicher, 2000, 2009). On the other hand, this situation might not mean there is a transformation of pre-existing identities into emergent identities. People might have been highly identified with an emergent group just because it becomes salient during the action. That is, being a protestor would be more salient and dominant compared to being, for example, an environmentalist, a socialist, or an $L G B T Q$. Whatever the case, the aforementioned transformation seems to occur just after the action started, as a function of intergroup confrontation as ESIM suggested. As such, digital platforms like microblogging and social media would contribute very little, if not any, to this process.

However, the other possibility also seems very plausible. That is, the influence of digital platforms on social identities might begin long before the collective action takes place. Different from the previous years, today people communicate and share information, ideas, and emotions instantaneously thanks to the widespread use of internet-based platforms (Jost et al., 2018). Digital technologies might facilitate consensus process through sharing a) information and ideas on the context that out-group treat the ingroup illegitimately, unfairly, and unjustly, b) the emotions as the appraisal of the unjust outgroup treatment, i.e. resentment, anger, c) the contents of the emergent group that is in the process of being formed, i.e. values and norms d) the route of the action.

Another point we have to note is that neither participation type nor WEIRDness of the sample as the potential moderators that were considered as to explain the heterogeneity was not found significant in the relationship between identification and collective action participation. Regarding the participation type, this result is in line with the theory of planned behavior (Ajzen, 1985), which suggests intention is the strongest predictor of behavior. It should, however, be stated that this result does not mean that intention predicts collective action participation. It just indicates that the effect of social identification is the same for these two types of measures. Nevertheless, it is noteworthy that one's identification with the 
relevant group predicts both collective action intentions and behaviors. As for WEIRDness, an increasing number of studies tested the social psychological models of collective action participation which placed the social identification in the heart of the model such as SIMCA in different contexts including non-weird countries (see van Zomeren, 2019). Moreover, numerous studies examined the "core motivations" of collective action (van Zomeren et al., 2008; van Zomeren, 2016) including social identification in non-weird contexts (see van Zomeren \& Louis, 2017). The vast majority of these studies provided similar findings with WEIRD samples that social identification is a strong predictor of collective action participation. Yet, Van Zomeren $(2016,2019)$ noted that although core motivations such as social identification might be similar across cultures, how they come into the fore and trigger action is context-sensitive. That is, these core motivations need to be unlocked by cultural and contextual conditions.

The current paper has also some limitations. First, although it is impossible to include qualitative research into the meta-analysis, this impossibility limits our understandings of how digital platforms contribute to the social identification process, and thus collective actions from the initial to the final phase (e.g., Smith et al., 2018). Second, non-WEIRD samples included in the current meta-analysis were from only five different cultures (China, Egypt, Hong Kong, Taiwan, and Turkey). Including more diverse cultural settings as a nonWEIRD might allow us to better comprehend cultural variations in the relationship between social identification and collective action participation via digital platforms. Third, though collective action covers a large range of collective behavior from sign campaign to marches, sit-in actions to physical encounters with the out-groups (e.g., police), we did not differentiate between them. We only make a distinction between actual behavior and behavioral intention. Although there is an assumption in collective action research that participation in all kinds of collective actions shares the same psychological mechanisms, some scholars argue that there 
are conceptual distinctions among offline collective actions, protests, riots, and uprisings (Radburn \& Stott, 2019; Wahlström, 2011). Further studies should focus on the moderator role of the distinctions between the action types.

\section{Conclusion}

Despite the limitations, the present meta-analysis provides support for the notion that social identification is still the basic psychological process of collective action participation in the Internet age, in contrast with the assumptions of connective action. The results revealed that there is a moderate to a strong positive relationship between social identification and participation in collective action. Moreover, our findings showed that group type moderate the relationship between social identification and collective action participation in the digital era, collective action participation has a stronger correlation with emergent group identification than pre-existing group identification. 
Author Contributions and Acknowledgments

All authors contributed to the research. Data analyses and interpretation were

performed by T. Ergiyen. All authors drafted the manuscript and approved the final version of the manuscript for submission. We declare that none of the authors have any conflict of interest. We confirm that the manuscript adheres to ethical guidelines specified in the APA Code of Conduct. We dedicated this study to George Floyd and the Black Lives Matter movement._All data and materials are accessible at https://osf.io/tf5zp/?view_only=e3c13743d63a4d5b889d369b3d5dc0dc 


\section{References}

Ajzen, I. (1985). From intentions to actions: A theory of planned behavior. In J. Kuhl \& J. Beckmann (Eds.), Action control, from cognition to behavior (pp. 11-39). New York: Springer-Verlag.

*Alberici, A., \& Milesi, P. (2013). The influence of the internet on the psychosocial predictors of collective action. Journal Of Community \& Applied Social Psychology, 23(5), 373-388. https://doi.org/10.1002/casp.2131

*Alberici, A., \& Milesi, P. (2016). Online discussion, politicized identity, and collective action. Group Processes \& Intergroup Relations, 19(1), 43-59. https://doi.org/10.1177/1368430215581430

*Alberici, A., \& Milesi, P. (2018). Online discussion and the moral pathway to identity politicization and collective action. Europe's Journal Of Psychology, 14(1), 143-158. https://doi.org/ 10.5964/ejop.v14i1.1507

Anduiza, E., Cristancho, C., \& Sabucedo, J. (2014). Mobilization through online social networks: the political protest of the indignados in Spain. Information, Communication \& Society, 17(6), 750-764.

https://doi.org/10.1080/1369118x.2013.808360

Arnett, J. J. (2016). The neglected 95\%: why American psychology needs to become less American. American Psychologist 63(7), 602-614. https://doi.org/10.1037/0003-066X.63.7.602

Atran, S., Medin, D. L., Lynch, E., Vapnarsky, V., Ucan, E. E., \& Sousa, P. (2001). Folkbiology doesn't come from folkpsychology: Evidence from Yukatek Maya in cross-cultural perspective. Journal of Cognition and Culture 1(1):3-42. https://doi.org/ 10.1163/156853701300063561 
*Ayanian, A., \& Tausch, N. (2016). How risk perception shapes collective action intentions in repressive contexts: A study of Egyptian activists during the 2013 post-coup uprising. British Journal Of Social Psychology, 55(4), 700-721. https://doi.org/10.1111/bjso.12164

Bennett, W., Breunig, C., \& Givens, T. (2008). Communication and political mobilization: Digital media and the organization of anti-Iraq war demonstrations in the U.S. Political Communication, 25(3), 269-289. https://doi.org/10.1080/10584600802197434

Bennett, W., \& Segerberg, A. (2012). The logic of connective action. Information, Communication \& Society, 15(5), 739-768. https://doi.org/10.1080/1369118x.2012.670661

Bennett, W., Segerberg, A., \& Walker, S. (2014). Organization in the crowd: peer production in large-scale networked protests. Information, Communication \& Society, 17(2), 232260. https://doi.org/ 10.1080/1369118x.2013.870379

*Besta, T., \& Zawadzka, A. (2019). Expansion of the self of activists and nonactivists involved in mass gatherings for collective action. Group Processes \& Intergroup Relations, 22(2), 182-199. https://doi.org/10.1177/1368430217735903

*Bilali, R., Godfrey, E., \& Freel, S. (2020). How an election loss leads to a social movement: Reactions to the 2016 U.S. presidential election among liberals predict later collective action and social movement identification. British Journal Of Social Psychology, 59(1), 227-247. https://doi.org/ 10.1111/bjso.12335

Bimber, B., Flanagin, A., \& Stohl, C. (2005). Reconceptualizing collective action in the contemporary media environment. Communication Theory, 15(4), 365-388. https://doi.org/10.1111/j.1468-2885.2005.tb00340.x 
Bliuc, A. M., McGarty, C., Reynolds, K., \& Muntele, D. (2007). Opinion-based group membership as a predictor of commitment to political action. European Journal of Social Psychology, 37(1), 19-32. https://doi.org/10.1002/ejsp.334

Carlisle, J. E., \& Patton, R. C. (2013). Is social media changing how we understand political engagement? An analysis of Facebook and the 2008 presidential election. Political Research Quarterly, 66(4), 883-895. https://doi.org/10.1177/1065912913482758

Castells, M. (2015). Networks of outrage and hope: Social movements in the Internet age. John Wiley \& Sons.

Chan, M. (2014). Social identity gratifications of social network sites and their impact on collective action participation. Asian Journal of Social Psychology, 17(2), 229-235. https://doi.org/10.1111/ajsp.12068

*Chan, M. (2015). Psychological antecedents and motivational models of collective action: examining the role of perceived effectiveness in political protest participation. Social Movement Studies, 15(3), 305-321. https://doi.org/ 10.1080/14742837.2015.1096192

*Chan, M. (2016). Media Use and the Social Identity Model of Collective Action: Examining the Roles of Online Alternative News and Social Media News. Journalism \& Mass Communication Quarterly, 94(3), 663-681. https://doi.org/10.1177/1077699016638837

*Chan, W., Cattaneo, L., Mak, W., \& Lin, W. (2017). From moment to movement: Empowerment and resilience as a framework for collective action in Hong Kong. American Journal Of Community Psychology, 59(1-2), 120-132. https://doi.org/10.1002/ajcp.12130

Chayinska, M., Minescu, A., \& McGarty, C. (2019). 'We fight for a better future for our country': Understanding the Ukrainian Euromaidan movement as the emergence of a 
social competition strategy. British Journal of Social Psychology, 58(1): 45-65. https://doi.org/10.1111/bjso.12283

*Cheng, G., Chan, D., \& Yeung, D. (2019). Correlates of Acceptance of Wealth Inequality: A Moderated Mediation Model. Frontiers In Psychology, 10. https://doi.org/10.3389/fpsyg.2019.00900

Cohen, J. (1960). A coefficient of agreement for nominal scales. Educational and psychological measurement, 20(1), 37-46. https://doi.org/10.1177/001316446002000104

Cohen, J. (1992). A power primer. Psychological bulletin, 112(1), 155. https://doi.org/10.1037//0033-2909.112.1.155

Cooper, H., Hedges, L. V., \& Valentine, J. C. (Eds.) (2009). The handbook of research synthesis and meta-analysis. New York, NY: Russell Sage Foundation.

*Dalgar, I., Sumer, N., Thomsen, L., \& IJzerman, H. (2020). Testing the relational motivational model of collective action. Manuscript in preparation.

Drury, J., \& Reicher, S. (1999). The intergroup dynamics of collective empowerment: Substantiating the social identity model of crowd behavior. Group Processes \& Intergroup Relations, 2(4), 381-402. https://doi.org/10.1177/1368430299024005

Drury, J., \& Reicher, S. (2000). Collective action and psychological change: The emergence of new social identities. British Journal of Social Psychology, 39, 579-604. https://doi.org/10.1348/014466600164642

Drury, J., \& Reicher, S. (2009). Collective psychological empowerment as a model of social change: Researching crowds and power. Journal Of Social Issues, 65(4), 707-725. https://doi.org/ 10.1111/j.1540-4560.2009.01622.x

Earl, J., \& Kimport, K. (2011). Digitally enabled social change: Activism in the internet age. Mit Press. 
Ellemers, N. (1993). The influence of socio-structural variables on identity enhancement strategies. European Review of Social Psychology, 4, $27-57$. https://doi.org/10.1080/14792779343000013

Garrett, R. K. (2006). Protest in an information society. A review of the literature on social movements and new ICTs. Information, Communication \& Society, 9(2), 202-224. https://doi.org/10.1080/13691180600630773

*Girerd, L., Ray, F., Priolo, D., Codou, O., \& Bonnot, V. (2020). "Free" not to engage: Neoliberal ideology and collective action. The case of the yellow vest movement. International Review Of Social Psychology, 33(1), 7. https://doi.org/10.5334/irsp.363

*Gotlieb, M., \& Thorson, K. (2017). Connected political consumers: transforming personalized politics among youth into broader repertoires of action. Journal Of Youth Studies, 20(8), 1044-1061. https://doi.org/10.1080/13676261.2017.1305101

Haslam, S., Turner, J., Oakes, P., McGarty, C., \& Reynolds, K. (1998). The group as a basis for emergent stereotype consensus. European Review Of Social Psychology, 8(1), 203239. https://doi.org/10.1080/14792779643000128

Harlow, S., \& Guo, L. (2014). Will the revolution be tweeted or Facebooked? Using digital communication tools in immigrant activism. Journal of Computer-Mediated Communication, 19(3), 463-478. https://doi.org/10.1111/jcc4.12062

Henrich, J., Boyd, R., Bowles, S., Camerer, C., Fehr, E., Gintis, H., ... \& Henrich, N. S. (2005). "Economic man" in cross-cultural perspective: Behavioral experiments in 15 small-scale societies. Behavioral and brain sciences, 28(6), 795-815. https://doi.org/10.1017/S0140525X05000142 
Henrich, J., Heine, S. J., \& Norenzayan, A. (2010a). The weirdest people in the world?. Behavioral and Brain Sciences, 33, 61-135. https://doi.org/10.1017/S0140525X0999152X

Henrich, J., Heine, S. J., \& Norenzayan, A. (2010b). Most people are not WEIRD. Nature, 466(7302), 29-29. https://doi.org/10.1038/466029a

Henrich, J., McElreath, R., Barr, A., Ensminger, J., Barrett, C., Bolyanatz, A., ... \& Lesorogol, C. (2006). Costly punishment across human societies. Science, 312(5781), 1767-1770. https://doi.org/10.1126/science.1127333

Higgins, J. P., \& Thompson, S. G. (2002). Quantifying heterogeneity in a meta-analysis. Statistics in medicine, 21(11), 1539-1558. https://doi.org/10.1002/sim.1186

Hogg, M. A., \& van Knippenberg, D. (2003). Social identity and leadership processes in groups. In M. P. Zanna (Ed.), Advances in Experimental Social Psychology, vol. 35 (pp. 1-52). San Diego, CA Academic Press.

*Hsiao, Y., \& Yang, Y. (2018). Commitment in the cloud? Social media participation in the sunflower movement. Information, Communication \& Society, 21(7), 996-1013. https://doi.org/10.1080/1369118x.2018.1450434

Jamovi project (2020). jamovi. (Version 1.1.9) [Computer Software]. Retrieved from https://www.jamovi.org.

*Ji, Y., Zhou, Y., \& Kim, S. (2017). A moderated mediation model of political collective action in Hong Kong: examining the roles of social media consumption and social identity. Asian Journal Of Communication, 27(5), 497-516. https://doi.org/10.1080/01292986.2017.1336777

Jost, J. T., Liviatan, I., van der Toorn, J., Ledgerwood, A., Mandisodza, A., \& Nosek, B. A. (2012). System justification: A motivational process with implications for social conflict. Justice and Conflicts, 315-327. 
http://doi.org/10.1007/978-3-642-19035-3_19

Jost, J. T., Barberá, P., Bonneau, R., Langer, M., Metzger, M., Nagler, J., ... Tucker, J. A. (2018). How social media facilitates political protest: Information, motivation, and social networks. Political Psychology, 39, 85-118. https://doi.org/10.1111/pops.12478

Kelly, G., \& Brienlinger, S. (1995). Attitudes, intentions, and behavior: A study of women's participation in collective action. Journal of Applied Social Psychology, 25, 14301445. https://doi.org/10.1111/j.1559-1816.1995.tb02625.x

*Kende, A., van Zomeren, M., Ujhelyi, A., \& Lantos, N. (2016). The social affirmation use of social media as a motivator of collective action. Journal Of Applied Social Psychology, 46(8), 453-469. https://doi.org/ 10.1111/jasp.12375

Klandermans, B. (1984). Mobilization and participation: Social-psychological expansisons of resource mobilization theory. American sociological review, 583-600. https://doi.org/10.2307/2095417

Klandermans, B. (1997). The social psychology of protest. Oxford: Blackwell Publishers.

Klein, O., Spears, R., \& Reicher, S. (2007). Social identity performance: Extending the strategic side of SIDE. Personality and Social Psychology Review, 11(1), 28-45. https://doi.org/10.1177/1088868306294588

Klein, R. A., Vianello, M., Hasselman, F., Adams, B. G., Adams, R. B., Jr., Alper, S., . . Nosek, B. A. (2018). Many Labs 2: Investigating variation in replicability across sample and setting. https://doi.org/10.31234/osf. io/9654g.

Lee, F., Chen, H., \& Chan, M. (2017). Social media use and university students' participation in a large-scale protest campaign: The case of Hong Kong's Umbrella Movement. Telematics And Informatics, 34(2), 457-469. https://doi.org/10.1016/j.tele.2016.08.005 
Leong, C., Pan, S., Bahri, S., \& Fauzi, A. (2019). Social media empowerment in social movements: power activation and power accrual in digital activism. European Journal Of Information Systems, 28(2), 173-204.

https://doi.org/10.1080/0960085x.2018.1512944

*Lu, C., Wan, C., Hui, P., \& Tong, Y. (2020). In Response to Cultural Threat: Cultural SelfAwareness on Collective Movement Participation. Journal Of Cross-Cultural Psychology, 51(1), 70-76. https://doi.org/10.1177/0022022119888795

*Mahfud, Y., \& Adam-Troian, J. (2019). “Macron demission!”: Loss of significance generates violent extremism for the Yellow Vests through feelings of anomia. Group Processes \& Intergroup Relations, 136843021988095. https://doi.org/10.1177/1368430219880954

McGarty, C., Bliuc, A. M., Thomas, E. F., \& Bongiorno, R. (2009). Collective action as the material expression of opinion-based group membership. Journal of Social Issues, 65(4), 839-857. https://doi.org/10.1111/j.1540-4560.2009.01627.x

McGarty, C., Thomas, E., Lala, G., Smith, L., \& Bliuc, A. (2014). New Technologies, New Identities, and the Growth of Mass Opposition in the Arab Spring. Political Psychology, 35(6), 725-740. https://doi.org/10.1111/pops.12060

*Morgan, G., \& Chan, W. (2016). Different paths to protest: predictors of collective action in the Occupy Movement. Journal Of Applied Social Psychology, 46(10), 565-582. https://doi.org/10.1111/jasp.12386

Morling, B., \& Lamoreaux, M. (2008). Measuring culture outside the head: A meta-analysis of individualism-collectivism in cultural products. Personality and Social Psychology Review 12:199-21. https://doi.org/10.1177\%2F1088868308318260

Mummendey, A., Kessler, T., Klink, A., \& Mielke, R. (1999). Strategies to cope with negative social identity: Predictions by social identity theory and relative deprivation 
theory. Journal of Personality and Social Psychology, 76, 229-245. https://doi.org/10.1037/0022-3514.76.2.229

Nekmat, E., Gower, K., Zhou, S., \& Metzger, M. (2015). Connective-collective action on social media: Moderated mediation of cognitive elaboration and perceived source credibility on personalness of source. Communication Research, 46(1), 62-87. https://doi.org/ 10.1177/0093650215609676

*Nekmat, E., \& Ismail, I. (2019). Issue-based micromobilization on social media: Mediated pathways linking issue involvement and self-network opinion congruity to expressive support. Computers In Human Behavior, 101, 51-59. https://doi.org/10.1016/j.chb.2019.07.008

Norenzayan, A., Smith, E. E., Kim, B. J., \& Nisbett, R. E. (2002). Cultural preferences for formal versus intuitive reasoning. Cognitive Science, 26(5), 653-84. https://doi.org/10.1207/s15516709cog2605_4

*Odağ, Ö., Uluğ, M., \& Solak, N. (2016). "Everyday I'm Çapuling”: Identity and collective action through social network sites in the Gezi Park Protests in Turkey. Journal of Media Psychology, 28(3), 148-159. https://doi.org/10.1027/1864-1105/a000202

Orwin, R. G. (1983). A fail-safe N for effect size in meta-analysis. Journal of educational statistics, 8(2), 157-159. https://doi.org/10.3102/10769986008002157

Park, N., \& Yang, A. (2012). Online environmental community members' intention to participate in environmental activities: An application of the theory of planned behavior in the Chinese context. Computers In Human Behavior, 28(4), 1298-1306. https://doi.org/ 10.1016/j.chb.2012.02.013

Platow, M. J., \& van Knippenberg, D. (2001). A social identity analysis of leadership endorsement: The effects of leader ingroup prototypicality and distributive intergroup 
fairness. Personality and Social Psychology Bulletin, 27(11), 1508-1519. https://doi.org/10.1177/01461672012711011

Priante, A., Ehrenhard, M., van den Broek, T., \& Need, A. (2018). Identity and collective action via computer-mediated communication: A review and agenda for future research. New Media \& Society, 20(7), 2647-2669. https://doi.org/10.1177/1461444817744783

Postmes, T., \& Brunsting, S. (2002). Collective action in the age of the internet. Social Science Computer Review, 20(3), 290-301. https://doi.org/10.1177/089443930202000306

Postmes, T., Spears, R., \& Lea, M. (2002). Intergroup differentiation in computer-mediated communication: Effects of depersonalization. Group Dynamics: Theory, Research, And Practice, 6(1), 3-16. https://doi.org/10.1037/1089-2699.6.1.3

Radburn, M., \& Stott, C. (2019). The social psychological processes of 'procedural justice': Concepts, critiques and opportunities. Criminology \& Criminal Justice, 19(4), 421438. https://doi.org/10.1177/1748895818780200

Reicher, S. (1996). 'The Crowd' century: Reconciling practical success with theoretical failure. British Journal Of Social Psychology, 35(4), 535-553. https://doi.org/10.1111/j.2044-8309.1996.tb01113.x

Reicher, S. D. (2001). The psychology of crowd dynamics. In M. Hogg \& S. Tindale (Eds.), Blackwell handbook of social psychology: Group processes (pp. 175-197). Oxford: Blackwell.

Reicher, S., Haslam, S. A., \& Hopkins, N. (2005). Social identity and the dynamics of leadership: Leaders and followers as collaborative agents in the transformation of social reality. Leadership Quarterly. 16(4), 547-568.

https://doi.org/10.1016/j.leaqua.2005.06.007 
Rhodes, R. E., \& Dickau, L. (2012). Experimental evidence for the intention-behavior relationship in the physical activity domain: A meta-analysis. Health Psychology, 31(6), 724. https://doi.org/10.1037/a0027290

*Sabucedo, J., Gómez-Román, C., Alzate, M., van Stekelenburg, J., \& Klandermans, B. (2017). Comparing protests and demonstrators in times of austerity: regular and occasional protesters in universalistic and particularistic mobilisations. Social Movement Studies, 16(6), 704-720. https://doi.org/ 10.1080/14742837.2017.1338940

*Schumann, S., \& Klein, O. (2015). Substitute or stepping stone? Assessing the impact of low-threshold online collective actions on offline participation. European Journal of Social Psychology, 45(3), 308-322. https://doi.org/ 10.1002/ejsp.2084

Simon, B., \& Klandermans, B. (2001). Politicized collective identity: A social psychological analysis. American psychologist, 56(4), 319-331. https://doi.org/10.1037/0003-066X.56.4.319

Smith, L. G. E., Gavin, J., \& Sharp, E. (2015). Social identity formation during the emergence of the occupy movement. European Journal of Social Psychology, 45(7), 818-832. https://doi.org/10.1002/ejsp.2150

Smith, L., Thomas, E., \& McGarty, C. (2015). "We must be the change we want to see in the world": Integrating norms and identities through social interaction. Political Psychology, 36(5), 543-557. https://doi.org/ 10.1111/pops. 12180

Smith, L., McGarty, C., \& Thomas, E. (2018). After Aylan Kurdi: How tweeting about death, threat, and harm predict increased expressions of solidarity with refugees over time. Psychological Science, 29(4). https://doi.org/10.1177/0956797617741107 
*Stewart, A., Leach, C., Bilali, R., Çelik, A., \& Cidam, A. (2019). Explaining different orientations to the 2013 Gezi Park demonstrations in Istanbul, Turkey. British Journal Of Social Psychology, 58(4), 829-852. https://doi.org/10.1111/bjso.12316

Stott, C., Ball, R., Drury, J., Neville, F., Reicher, S., Boardman, A., \& Choudhury, S. (2018). The evolving normative dimensions of 'riot': Towards an elaborated social identity explanation. European Journal Of Social Psychology, 48(6), 834-849. https://doi.org/ 10.1002/ejsp.2376

Stott, C., \& Reicher, S. (1998). Crowd action as intergroup process: introducing the police perspective. European Journal Of Social Psychology, 28(4), 509-529.

Stürmer, S., \& Simon, B. (2004). Collective action: Towards a dual-pathway model. European Review Of Social Psychology, 15(1), 59-99. https://doi.org/10.1080/10463280340000117

Tang, G., \& Lee, F. (2013). Facebook use and political participation: The impact of exposure to shared political information, connections with public political actors, and network structural heterogeneity. Social Science Computer Review, 31(6), 763-773. https://doi.org/10.1177/0894439313490625

Tajfel, H., \& Turner, J. C. (1986). An integrative theory of intergroup conflict. In W. G. Austin \& S. Worchel (Eds.), The social psychology of intergroup relations (pp. 3347). Monterey, CA: Brooks/Cole.

*Thomas, E., McGarty, C., Lala, G., Stuart, A., Hall, L., \& Goddard, A. (2015). Whatever happened to Kony2012? Understanding a global Internet phenomenon as an emergent social identity. European Journal Of Social Psychology, 45(3), 356-367. https://doi.org/10.1002/ejsp.2094 
Thomas, E., Mavor, K., \& McGarty, C. (2012). Social identities facilitate and encapsulate action-relevant constructs. Group Processes \& Intergroup Relations, 15(1), 75-88. https://doi.org/10.1177/1368430211413619

Thomas, E., McGarty, C., \& Mavor, K. (2009). Aligning identities, emotions, and beliefs to create commitment to sustainable social and political action. Personality And Social Psychology Review, 13(3), 194-218. https://doi.org/10.1177/1088868309341563

Tufekci, Z. (2013). "Not This One”: Social movements, the attention economy, and microcelebrity networked activism. American Behavioral Scientist, 57(7), 848-870. https://doi.org/ 10.1177/0002764213479369

Turner, J. C., \& Haslam, S. A. (2001). Social identity, organizations, and leadership. In M. E. Turner (Ed.), Groups at work: Theory and research (pp. 25-65). Mahwah, NJ: Lawrence Erlbaum.

*Uysal, M. S., \& Akfirat, S. (2020). Formation of emergent identity:Applying EMSICA into Gezi Park protests. Manuscript in preperation.

Vaast, E., Safadi, H., Lapointe, L., \& Negoita, B. (2017). Social Media Affordances for Connective Action: An Examination of Microblogging Use During the Gulf of Mexico Oil Spill. MIS Quarterly, 41(4), 1179-1205. https://doi.org/10.25300/misq/2017/41.4.08

van Zomeren, M. (2013). Four core social-psychological motivations to undertake collective action. Social and Personality Psychology Compass, 7(6), 378-388. https://doi.org/10.1111/spc3.12031

van Zomeren, M. (2016). Building a Tower of Babel? Integrating core motivations and features of social structure into the political psychology of political action. Advances in Political Psychology, 37(1), 87-114. https://doi.org/10.1111/pops.12322 
van Zomeren, M. (2019). Toward a cultural psychology of collective action: Just how "core" are the core motivations for collective action? Journal of Pacific Rim Psychology, 13, e15. https://doi.org/10.1017/prp.2019.7

van Zomeren, M., \& Louis, W. R. (2017). Culture meets collective action: Exciting synergies and some lessons to learn for the future. Group Processes \& Intergroup Relations, 20(3), 277-284. https://doi.org/10.1177/1368430217690238

van Zomeren, M., Postmes, T., \& Spears, R. (2008). Toward an integrative social identity model of collective action: A quantitative research synthesis of three sociopsychological perspectives. Psychological Bulletin, 134(4), 504-535. https://doi.org/10.1037/0033-2909.134.4.504

van Zomeren, M., Spears, R., Fischer, A. H., \& Leach, C. W. (2004). Put your money where your mouth is! Explaining collective action tendencies through group-based anger and group efficacy. Journal of personality and social psychology, 87(5), 649-

664. https://doi.org/10.1037/0022-3514.87.5.649

*Velasquez, A., Montgomery, G., \& Hall, J. (2019). Ethnic minorities' social media political use: How ingroup identification, selective exposure, and collective efficacy shape social media political expression. Journal Of Computer-Mediated Communication, 24(4), 147-164. https://doi.org/ 10.1093/jcmc/zmz007

Vestergren, S., Drury, J., \& Chiriac, E. H. (2018). How collective action produces psychological change and how that change endures over time: A case study of an environmental campaign. British Journal of Social Psychology, 57(4), 855-877. https://doi.org/10.1111/bjso.12270

Wahlström, M. (2011). Taking control or losing control? Activist narratives of provocation and collective violence. Social Movement Studies, 10(4), 367-385. https://doi.org/10.1080/14742837.2011.614107 
Waxman, S., \& Medin, D. L. (2007). Experience and cultural models matter: Placing firm limits on childhood anthropocentrism. Human Development 50(1):23-30. http://doi.org/10.1159/000097681

Webb, T. L., \& Sheeran, P. (2006). Does changing behavioral intentions engender behavior change? A meta-analysis of the experimental evidence. Psychological Bulletin, 132, 249-268. https://doi.org/10.1037/0033-2909.132.2.249

*Wlodarczyk, A., Basabe, N., Páez, D., \& Zumeta, L. (2017). Hope and anger as mediators between collective action frames and participation in collective mobilization: The case of 15-M. Journal Of Social And Political Psychology, 5(1), 200-223. https://doi.org/10.5964/jspp.v5i1.471

*Wollast, R., Lüders, A., Li, M., Wu, H., Beattie, P., Nugier, A., \& Guimond, S. (2020). Understanding the role of social media in collective action: a comparison between the Yellow Vests movement in France and the Anti-ELAB protests in Hong Kong. LAPSCO, UCA, France. Manuscript in preparation.

Wright, S., Taylor, D., \& Moghaddam, F. (1990). Responding to membership in a disadvantaged group: From acceptance to collective protest. Journal of Personality and Social Psychology, 58(6), 994-1003. https://doi.org/10.1037/0022-3514.58.6.994

*Zhou, Q., \& Qiu, H. (2020). Predicting online feminist engagement after MeToo: a study combining resource mobilization and integrative social identity paradigms. Chinese Journal Of Communication, 1-19. https://doi.org/10.1080/17544750.2020.1725077

*Zúñiga, H. G. de, Jung, N., \& Valenzuela, S. (2012). Social media use for news and 1ndividuals' social capital, civic engagement and political participation. Journal Of Computer-Mediated Communication, 17(3), 319-336. https://doi.org/10.1111/j.1083$\underline{6101.2012 .01574 . x}$ 
*Zúñiga, H. G. de, Molyneux, L., \& Zheng, P. (2014). Social media, political expression, and political participation: Panel analysis of lagged and concurrent relationships. Journal of Communication, 64(4), 612-634. https://doi.org/10.1111/jcom.12103

$*=$ Articles included in the meta-analysis 
Figure 1

Selection Process of Included Publications

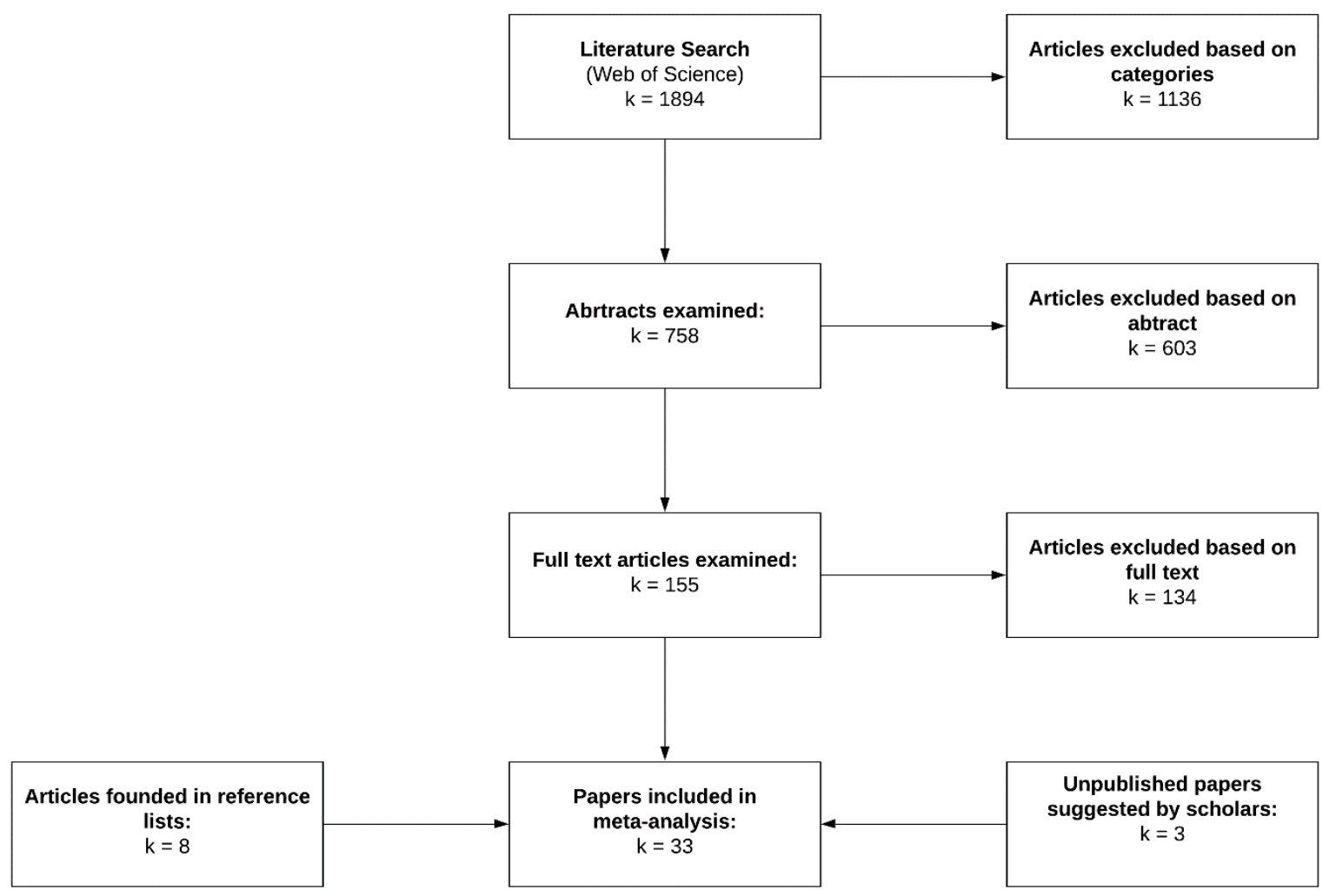


Table 1

Descriptive Information of all Samples

\begin{tabular}{|c|c|c|c|c|c|}
\hline Label & $N$ & Female $(\%)$ & Male $(\%)$ & Age $(S D)$ & Country \\
\hline Alberici2013-1 & 71 & 25.35 & 74.65 & $38.2(11.2)$ & Italy \\
\hline Alberici2013-2 & 147 & 56.46 & 43.54 & $32.5(13.4)$ & Italy \\
\hline Alberici2016-2 & 192 & 100 & 0 & $47.11(12.2)$ & Italy \\
\hline Alberici2018 & 143 & 37.06 & 62.94 & $49.2(12.5)$ & Italy \\
\hline Ayanian2016-1,2 & 146 & 32.19 & 67.81 & $26.20(-)$ & Egypt \\
\hline Besta2019-1 & 181 & 59.67 & 40.33 & $25.1(8.90)$ & Poland \\
\hline Besta2019-2 & 262 & 55.73 & 44.27 & $25.6(6.70)$ & Poland \\
\hline Bilali2020 & 913 & 60.8 & 39.2 & $38.87(12.12)$ & US \\
\hline Chan2015 & 816 & 52 & 48 & - & Hong Kong \\
\hline Chan2016 & 818 & 51.7 & 48.3 & - & Hong Kong \\
\hline Chan2017 & 589 & 68.9 & 31.1 & $20.8 \quad(3.03)$ & Hong Kong \\
\hline Cheng2019 & 866 & 48 & 52 & - & Hong Kong \\
\hline Dalgar2020* & 641 & 55.07 & 33.23 & $28.49(0.74)$ & Turkey \\
\hline Girerd2020-1 & 489 & 61.65 & 36.91 & $41.95(16.24)$ & France \\
\hline Girerd2020-2 & 201 & 54.2 & 45.8 & $37.61(14.7)$ & France \\
\hline Gotlieb2017 & 651 & 49.8 & 50.2 & $24.24(3.27)$ & US \\
\hline Hsiao2018 & 801 & 48.81 & 49.81 & $23.59(3.91)$ & Taiwan \\
\hline Ji2017 & 639 & 61.3 & 38.7 & $22(0.69)$ & Hong Kong \\
\hline Kende2016-1 & 148 & 52 & 48 & $29.3(12.4)$ & Hungary \\
\hline Kende2016-2 & 261 & 78.2 & 21.8 & $21.34(3.14)$ & Hungary \\
\hline Lu2020 & 189 & 70.37 & 29.63 & $21.26(2.56)$ & Hong Kong \\
\hline Mahfud2019-1 & 776 & 50.39 & 28.48 & $32.02(15.19)$ & France \\
\hline Mahfud2019-2 & 511 & 89.6 & 9.1 & $19.39(3.04)$ & France \\
\hline Morgan2016 & 193 & 53 & 47 & $32.41(14.00)$ & US \\
\hline Nekmat2019 & 684 & 54 & 46 & $27.1(6.18)$ & Singapore \\
\hline Odag2016 & 1127 & 45.87 & 44.81 & $30.11(9.72)$ & Turkey \\
\hline Park2012 & 211 & 49.8 & 47.9 & $25.37(6.39)$ & China \\
\hline Sabucedo2017 & 285 & 43.4 & 56.6 & $40(14.49)$ & Spain \\
\hline Schumann2015-1 & 76 & 80.3 & 19.7 & $20.96(3.93)$ & Belgium \\
\hline Schumann2015-2 & 59 & 84.5 & 15.5 & $19.48(2.33)$ & Belgium \\
\hline Stewart2019-2 & 327 & 48.32 & 38.84 & $32.38(13.79)$ & Turkey \\
\hline Thomas 2015 & 299 & 51.37 & 48.63 & $20.73(4.68)$ & Australia \\
\hline Velasquez2019 & 503 & 50.1 & 49.9 & $38.61(14.28)$ & US \\
\hline Wlodarczyk2017 & 638 & 56.6 & 43.4 & $31.66(11.39)$ & Spain \\
\hline Wollast2020* & 169 & 58.58 & 40.24 & $25.81(9.03)$ & Hong Kong \\
\hline Uysal2020* & 403 & 63.52 & 36.48 & $28.96(8.64)$ & Turkey \\
\hline Zhou2020 & 721 & 100 & 0 & $26.90(-)$ & China \\
\hline Zuniga2012 & 475 & 67 & 33 & $45.76(12.45)$ & US \\
\hline Zuniga2014 & 312 & 67 & 33 & $49.32(12.25)$ & US \\
\hline
\end{tabular}

Note. $*=$ Unpublished paper 
Table 2

List of Non-WEIRD and WEIRD Countries

Non-WEIRD Countries ( $N$ of study)

China (2), Egypt (2), Hong Kong (7),

Taiwan (1), and Turkey (4).
WEIRD Countries ( $N$ of study)

Australia (1), Belgium (2), France (4),

Hungary (2), Italy (4), Poland (2),

Singapore (1), Spain (2), and US (6). 
Figure 2

Forest Graph of Average Weighted Effect Size of Social Identification on Participation to Collective Action and the Effect Sizes and Confidence Intervals

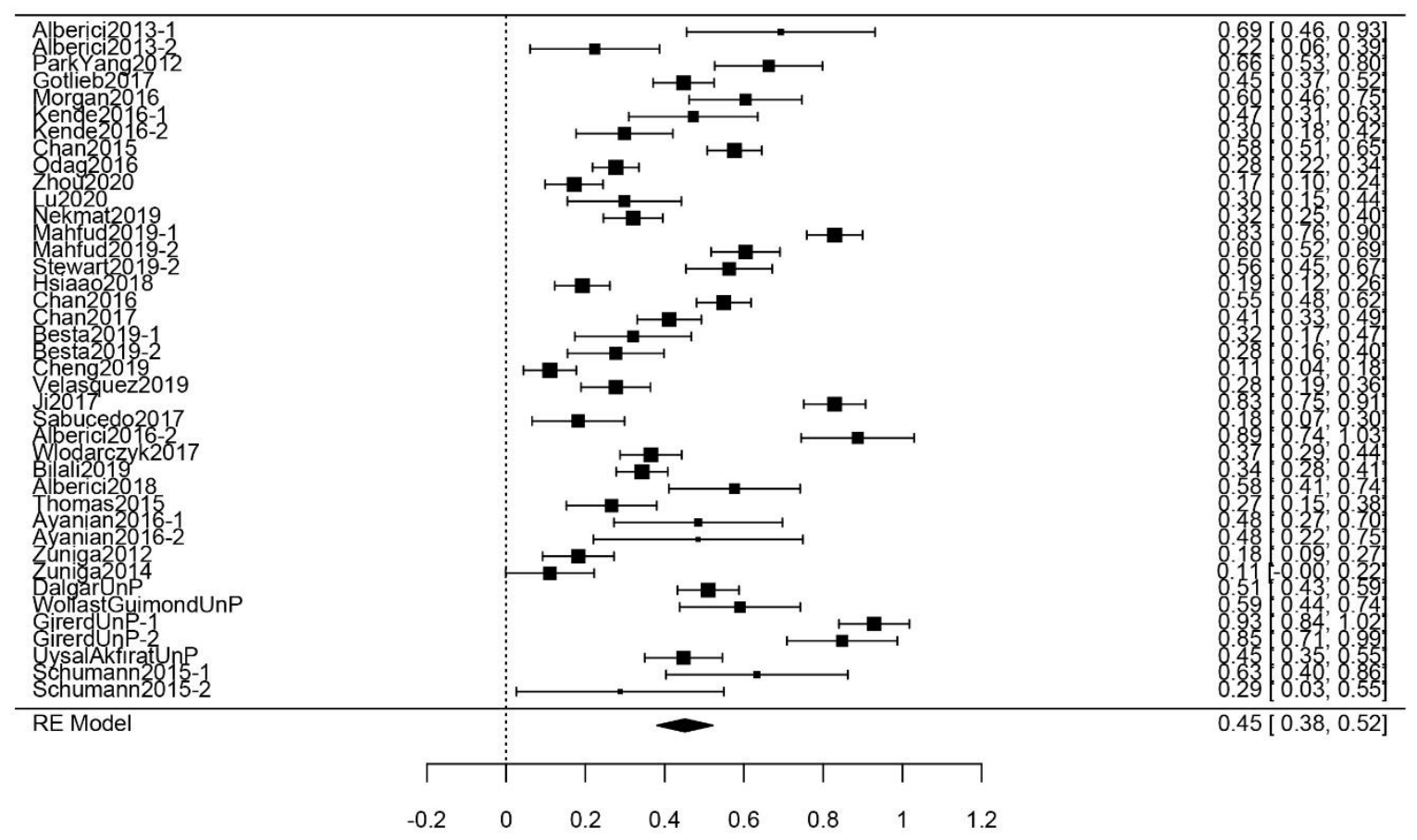


Figure 3

Funnel Plot for the Effect of Social Identification and Participation to Collective Action

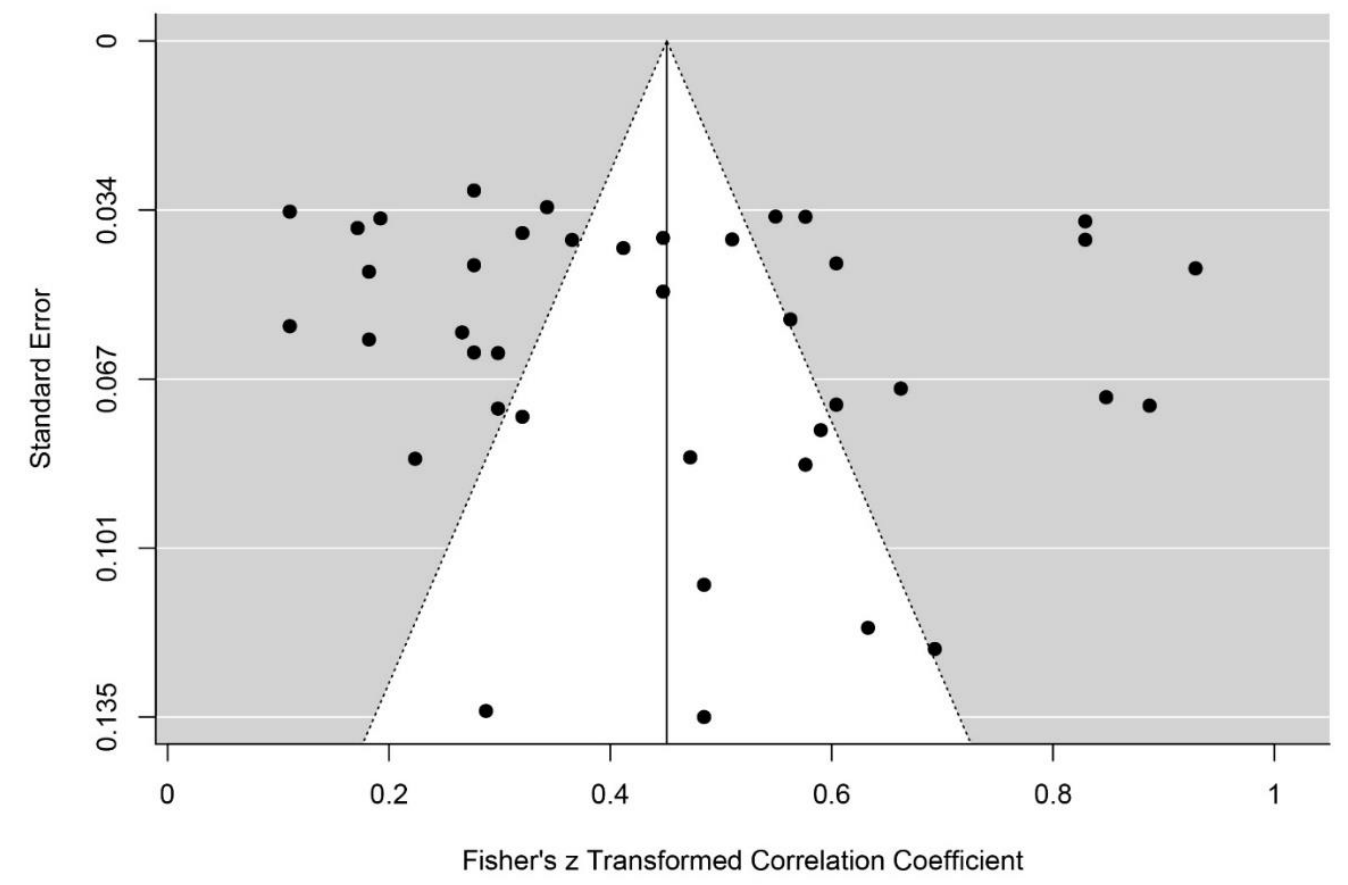


Table 3

Summary of the Moderators on the Relationships Between Social Identification and

Participation to Collective Action

\begin{tabular}{lcccc}
\hline Moderator & $r_{z}$ & $95 \%$ CI & $k$ & $p$ \\
\hline Total & $.45^{*}$ & {$[0.381,0.522]$} & 40 & .010 \\
Group Type & & & & \\
$\quad$ Group Identity & $.34 *$ & {$[0.228,0.450]$} & 15 & \\
$\quad$ Protestor & $.52^{*}$ & {$[0.436,0.600]$} & 25 & .474 \\
Action Type & & & & \\
$\quad$ Intention & $.48^{*}$ & {$[0.379,0.577]$} & 20 & .887 \\
$\quad$ Participation & $.43 *$ & {$[0.325,0.528]$} & 20 & \\
Weirdness & & & & \\
$\quad$ Weird & $.46^{*}$ & {$[0.357,0.555]$} & 24 & \\
Non-Weird & $.44 *$ & {$[0.345,0.543]$} & 16 &
\end{tabular}

Note: CI, confidence interval; $k$, number of studies; $p, p$ values from moderation analysis $* p<$ .001 . 